\title{
Hemato-Biochemical and Therapeutic Trials on Sarcoptic Mange in Camels
}

\author{
P. R. Aziz ${ }^{1 *}$, S. Marodia ${ }^{2}$, P. I. Ganesan ${ }^{1}$ and C. S. Sharma ${ }^{3}$ \\ ${ }^{1}$ Department of Veterinary Medicine, Apollo College of Veterinary Medicine, India \\ ${ }^{2}$ Department of Veterinary Clinical Complex, Apollo College of Veterinary Medicine, India \\ ${ }^{3}$ Apollo College of Veterinary Medicine Jamdoli, Agra Road, Jaipur, Rajasthan, India 302031 \\ *Corresponding author
}

Ke y w o r d s
Azadirachta indica,
Camel,
Cypermethrin,
Hemato-
biochemical
analysis,
Ivermectin,
Sarcoptes scabiei
var cameli, Vetade
Article Info
Accepted:
22 February 2020
Available Online:
10 March 2020

\section{Introduction}

Sarcoptic mange is the second most important problematic disease of camels after Trypanosomiasis (Nayel and Abu-Samra, 1986). Scabies caused by Sarcoptes scabiei var cameli is a serious, highly contagious and economically important skin disease of the camel (Pegram and Higgins, 1992). Camels,
Ten camels showing typical clinical lesions of itching, pruritus, biting and rubbing against objects, alopecia, erythema, keratinization, thickening, corrugations and wrinkling of the skin, exudation and bleeding, fissured skin and scab formation were identified. The skin scrapings were collected from the edges of skin lesions in clean small size plastic jars separately, each duly marked for identification of the individual animal. Sarcoptes scabiei var cameli mites were identified on the basis of their characteristic morphological features. Blood from these camels was collected for Hemato-biochemical analysis at the start of each treatment to find out the effect of mange infestation on the blood physiology of animals. The results reveal that $\mathrm{Hb}, \mathrm{PCV}$, TEC showed a decreasing trend than the normal range indicative of anemia in the diseased animals. Among the biochemical parameters, Total Protein, Albumin, Globulin was decreased. TLC, Neutrophils, Eosinophils, Lymphocytes, Basophils, Monocytes and AST, ALT, ALKP, LDH, Bilirubin, BUN was increased. Treatment trial was started by dividing the ten camels into threegroups. On Group 1, $40 \%$ concentration of Azadirachta indica was applied, on Group 2, Cypermethrin was applied, on Group 3, $40 \%$ concentration of Azadirachta indica was applied and additionally Injection Ivermectin and Injection Vetade were also given. After some days again blood samples were taken for Hemato-biochemical analysis which showed a satisfactory response in all the groups. The treatment given to the Group 3 was best among the three therapeutic trial groups. 
frequently and sudden in onset. It is also ranked as one of the most serious and important disease of the camels. Sarcoptic mange infestation is very common in the areas of thin skin, the head, neck, flanks, medial aspect of thighs or inguinal region, mammary glands and prepuce. The head is usually affected very rapidly as the animal uses its teeth for scratching the affected areas. Besides linking the occurrence of the disease with poor camel management, malnutrition and contact with infected objects, the stray and infected camels also often become a focus of infecting the healthy animals when mingling with them particularly at watering places for drinking purpose (Abdel-Rehman et al., 2001).

Sarcoptes is a burrowing mite as it penetrates deeply through the skin surface of the infected camel. This burrowing of mites in the skin helps these parasites lead to intense pruritus and exudative dermatitis. In pruritus, mites penetrate deep into muscular areas, damaging the flesh and lowering the quality of meat. The early inflammatory reaction of the host body towards the mites becomes evident in the shape of small popular elevations, invasion and injuries leading to formation of hairless areas, scaly crust formation or scabs on the affected parts and the skin become dark and thickened. Skin of mangy camel show hemorrhages, and subcutaneous odema after the development of fissures in the underlying epidermis (Kumar et al., 1992; Amer et al., 2006).

The fertilized female mites create winding burrows or tunnels in the upper layers of the epidermis of the skin of the host animal and feeding on the serous exudate, a liquid oozes from the damaged tissues. The female mites lays about 40-50 fertilized eggs in these tunnels which hatch in 3-5 days into a six legged larvae. These larvae immediately crawl to the surface and burrow themselves in the superficial layers of the skin and create small molting pockets. In these molting pockets, the larvae molt to next stages of nymph and adult. The adult male then emerges and seeks a female either in the molting pocket or on the surface of skin. After fertilization the female produces new tunnels, either de novo or, by extension, of the molting pockets, lays eggs in these tunnels and a new life cycle starts. The entire life cycle of Sarcoptic mange is completed in 17-21 days.

New hosts can be infected through direct transmission by contact between the animals, presumably from larvae, nymph or adult mites, which are commonly present on the skin surface of the infected animal. Indirect transmission of infestation can also take place through the objects or fomites having mange infection, which come into contact with the affected camel, such as harnesses, blankets, baggage tack, tents and tree trunks (Richard, 1987). The pruritus increases as the mites penetrate deeper in the skin (Driot et al., 2011, Bekele et al., 2012). Based on the rate of infection camels can be seriously disturbed by the Sarcoptic infestation as they may stop grazing which can lead to a rapid fall in milk production, and deterioration of health condition. With the increase in the irritation due to scabies, the camel rubs, bites and scratches the affected areas in an attempt to reduce the itchiness.

Due to rubbing, biting or scratching, the mites move to the periphery affecting the healthy tissues and resultantly affected area spreads. As the disease prolongs, the skin becomes excoriated, leading to hair loss and the development of scabs. These scabs in turn may be rubbed away and a red surface developed. The animal becomes restless due to severe Sarcoptic mange infestation and involvement of most of the body surface. If the diseased animal is not treated in time, the animal loses its health condition, become 
emaciated and within two, three weeks the acute stage of disease may give way to more chronic state (Driot et al., 2011).

Sarcoptic mites rarely survive long off the host under natural conditions. A continuous direct contact of animal keepers with their camels can also lead to transmission of diseased condition in human beings which is termed as pseudo-scabies. Transmission of infection from camel to man usually takes place during milking, handling or riding. The main symptoms of pseudo-scabies can therefore be seen in the inter-digital spaces of the hands, on the wrists, forearms, the elbows, the axillary folds and inner side of the thighs. Once a herd is infected with Sarcoptic mange, continuous reinfection of the disease occurs (Premalatha et al., 2010). Sarcoptic mange is usually considered to be a seasonal disease and is often reported severe during the winter months as in cold weather the disease had an acute course. However, there is some evidence that in some countries hot weather predisposes to acute outbreaks of camel mange and in the cooler, winter season the rate of mange infestations are at the lowest. In the summer the activity of the mite seems to decline or disease becomes chronic. Dietary intake is an important factor in mange infestation. Nomadic camels on a low nutrition plane, probably carrying heavy worm burdens in hot desert conditions are likely, therefore, to be highly prone to Sarcoptes at this time (Dinka et al., 2010). During such periods of great activity, the mites are readily transmissible from one animal to other animals (Richard, 1987).

Mange can easily be diagnosed clinically from the occurrence of pruritus, depilation, alopecia, thickened skin, folds around the joints and encrusted plaques being the main characteristics of this parasitosis. In order to control this zoonotic disease, it is essential to treat both camel and man along with effective checks over other predisposing factors of the disease such as hygiene and nutritional requirements of the animals. The skin diseases like the scabies both in human beings and animals are being treated with a variety of allopathic drugs now-a-days, but the role of herbal plants in use since centuries in different shapes cannot be ignored at all, especially in the rural lifestyle. Further with the continuous use of different acaricidal drugs, the issue of resistance development has come across as a challenge for the researchers to find some alternatives for the purpose. Accordingly the research work on the use of traditional herbal medicines is gaining attention day by day.

\section{Materials and Methods}

Ten camels showing typical clinical lesions of itching, pruritus, biting and rubbing against objects, alopecia, erythema, keratinization, thickening, corrugation and wrinkling of the skin, exudation and bleeding, fissured skin and scab formation were identified. (Fig.2). Each camel was restrained properly and the hairs were clipped from the margins of the lesions with the help of scissors and then the area was cleaned with a $10 \%$ solution of $\mathrm{KOH}$. After cleaning and letting the area dry, the lesions were scraped from the margins with the help of a fresh razor blade in such a manner till the blood oozes out of the site. The reason of scraping deeply is that some mange / mite may burrow deeply in skin while some remain on the shallow surface of the skin. The skin scrapings were collected from the edges of skin lesions in clean small size plastic jars separately, each duly marked for identification of the individual animal. Sarcoptes scabiei var cameli mites were identified on the basis of their characteristic morphological features (Georg, 1985). (Fig.1) Sarcoptes scabiei var cameli mites were identified on the basis of their morphological characteristic features such as circular outline 
having four pairs of short and stumpy legs. The third and fourth pair of legs donot project beyond the body margins (Nayel and AbuSamra, 1986, Arora, 2003).

\section{Hemato-biochemical studies}

Blood from these camels was collected for Hemato-biochemical analysis on day zero, i.e. at the start of each treatment to find out the effect of mange infestation on the blood physiology of animals. Two blood samples with the help of disposable syringe were collected from the jugular vein, one in a tube containing the Na2-salt of EDTA for the hemogram / study of Hemoglobin (Hb), Packed Cell Volume (PCV), Total Erythrocyte Count (TEC), Total Leukocyte Count (TLC), and Differential Leukocyte count (Neutrophils, Eosinophils, Lymphocytes, Monocytes and Basophils). The second sample of blood was collected in a tube without anticoagulant for the subsequent serum collection for the study of Total Proteins, Albumin, Globulin, Bilirubin, BUN, Aspartate Aminotransferase (AST), Alanine Aminotransferase (ALT), Alkaline phosphatase (ALKP) and Lactate Dehydrogenase (LDH). The blood samples of camels treated with different medicines were again taken in a similar manner at the end of treatment (Day-30) to make its comparison with findings of day zero or before treatment.

\section{Therapeutic trials}

A total of ten camels which were found positive for Sarcopticosis were divided into three groups, Group 1 and Group 2 have three camels each and Group 3 has four camels. 40 $\%$ concentration of Azadirachta indica (Neem) was applied once a week, for a total of four applications to the camels of Group 1 . On the $22^{\text {nd }}$ day of treatment, two camels showed complete recovery and one camel showed partial recovery as was observed from the clinical signs. The camel which showed partial recovery was again given an application of Neem. On the $30^{\text {th }}$ day the camel recovered completely.

Cypermethrin was used topically once a week, for a total of four applications at the rate of $1 \mathrm{ml} /$ liter of water to the camels of Group 2. On the $25^{\text {th }}$ day of treatment, one camel showed complete recovery and two camels showed partial recovery as was observed from the clinical signs. The camel which showed partial recovery was again given an application of Cypermethrin. On the $30^{\text {th }}$ day the camel also recovered completely. $40 \%$ concentration of Neem was applied once a week, for a total of four applications, Injection Ivermectin @ $0.2 \mathrm{mg} / \mathrm{kg} \mathrm{BW}$, once a week, for a total of four injections and Injection Vetade $10 \mathrm{ml}$ per camel, once a week, for a total of four injections was given to the camels of Group 3. Complete recovery in all the camels was observed on $15^{\text {th }}$ day of treatment. It was also noted that camels in this group improved clinically earlierly and gained more weight than Group 1 and 2. There was no apparent adverse reaction to treatment in any of the study groups.

\section{Results and Discussion}

The results of different Hematological parameters before and after the treatment were studied to ascertain the changes in their values and to find out the effect of mange infestation on the blood physiology of camels. The mean averages of these parameters are presented in Table-1. All these Hematological parameters were found approaching towards normality after treatment and recovery from the mange infestation.

The results of different biochemical parameters before and after treatment were studied to ascertain the changes in their values. The mean averages of these 
parameters are presented in Table-2. All these biochemical parameters were found approaching towards normality after treatment and recovery from the mange infestation.

The results reveal that $\mathrm{Hb}, \mathrm{PCV}$, TEC showed a decreasing trend than the normal range indicative of anemia in the diseased animals, as also reported by Parmar et al., 2005, Gorak Mal et al., 2006, Rathod et al., 2008, Premalatha et al., 2010, Momenah, 2014, Arul, 2016, Prajapati et al., 2018. Mange mites abrade the skin surface and feed on exudates and blood from small surface haemorrhages leading to decrease in haemoglobin concentration and RBC value.
The decrease in $\mathrm{Hb}$ concentration might have been due to decrease in total erythrocyte counts.

TLC was increased as also reported by Parmar et al., 2005 and Premalatha et al., 2010. Neutrophils, Basophils and Monocytes were increased as also reported by Arul, 2016. Eosinophils and Lymphocytes were increased as also reported by Parmar et al., 2005, Premalatha et al., 2010, Arul, 2016. The results revealed that Total protein showed a decreased value as also reported by Parmar $e t$ al., 2005, Arul, 2016 and Prajapati et al., 2018. Albumin showed a decreased value as also reported by Parmar et al., 2005, Arul, 2016.

Table.1 Hematological findings

\begin{tabular}{|l|l|l|l|l|l|}
\hline Parameters & Range & $\begin{array}{l}\text { Pre- } \\
\text { treatment }\end{array}$ & Group 1 & Group 2 & Group 3 \\
\hline Hb $(\mathbf{g} / \mathbf{d l})$ & $7.2-13.2$ & $5.7-6.9$ & $6.1-6.3$ & $5.9-6.6$ & $6.8-7.5$ \\
\hline PCV $(\mathbf{\%})$ & $24-51$ & $18-23$ & $21-25$ & $20-24$ & $26-28$ \\
\hline TEC $(\mathbf{1 0} / \boldsymbol{\mu L})$ & $3.15-7.55$ & $2.75-4.53$ & $4.04-5.43$ & $3.95-5.19$ & $5.58-6.29$ \\
\hline TLC $(\mathbf{1 0} / \boldsymbol{\mu L})$ & $4.45-16.05$ & $12.67-26.86$ & $6.76-10.72$ & $5.53-7.98$ & $8.95-11.50$ \\
\hline $\mathbf{N}(\mathbf{\%})$ & $24-45$ & $38-62$ & $34-46$ & $36-57$ & $32-40$ \\
\hline $\mathbf{E}(\mathbf{\%})$ & $3-9$ & $4-12$ & $4-8$ & $5-10$ & $3-7$ \\
\hline $\mathbf{L}(\mathbf{\%})$ & $40-59$ & $56-73$ & $52-64$ & $55-68$ & $48-56$ \\
\hline $\mathbf{M}(\mathbf{\%})$ & $2-7$ & $3-9$ & $2-6$ & $2-8$ & $2-7$ \\
\hline $\mathbf{B}(\mathbf{\%})$ & $0-1$ & $0-2$ & $0-1$ & $0-2$ & $0-1$ \\
\hline
\end{tabular}

Table.2 Biochemical findings

\begin{tabular}{|l|l|l|l|l|l|}
\hline Parameters & Range & Pre-treatment & Group 1 & Group 2 & Group 3 \\
\hline TP $(\mathbf{g} / \mathbf{d L})$ & $5.97-10.67$ & $3.24-4.68$ & $5.47-5.76$ & $4.48-5.77$ & $6.45-7.87$ \\
\hline Alb. $(\mathbf{g} / \mathbf{d l})$ & $1.22-7.75$ & $1.03-2.24$ & $1.45-1.72$ & $1.23-1.68$ & $1.79-2.12$ \\
\hline Glo. $(\mathbf{g} / \mathbf{d L})$ & $3.10-4.85$ & $2.68-3.02$ & $3.67-3.90$ & $2.73-3.27$ & $3.82-4.44$ \\
\hline Bili. $(\mathbf{m g} / \mathbf{d l})$ & $1.15-1.65$ & $2.74-3.05$ & $2.45-2.55$ & $2.24-2.41$ & $1.86-2.34$ \\
\hline BUN (mmol/l) & $2.6-8.05$ & $7.97-9.08$ & $7.40-8.09$ & $7.92-9.00$ & $6.23-7.65$ \\
\hline AST $(\boldsymbol{\mu} / \mathbf{L})$ & $84.1-161.8$ & $234.65-240.65$ & $216.67-231.23$ & $222.78-226.89$ & $210.52-219.78$ \\
\hline ALT $(\boldsymbol{\mu} / \mathbf{L})$ & $7.1-21.5$ & $25.65-27.15$ & $21.90-23.03$ & $24.03-26.34$ & $17.64-19.31$ \\
\hline ALKP $(\boldsymbol{\mu} / \mathbf{L})$ & $52-71$ & $74-80$ & $63-67$ & $71-73$ & $58-60$ \\
\hline LDH $(\mathbf{I U / L )}$ & $350-380$ & $426-543$ & $389-394$ & $412-417$ & $403-406$ \\
\hline
\end{tabular}




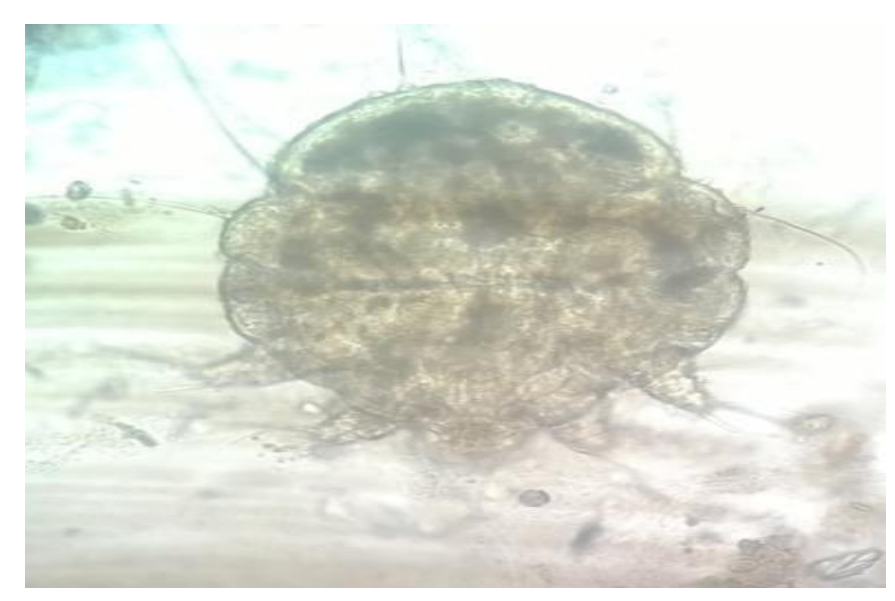

Fig.1 Sarcoptes scabiei var cameli in $40 \mathrm{X}$ magnification

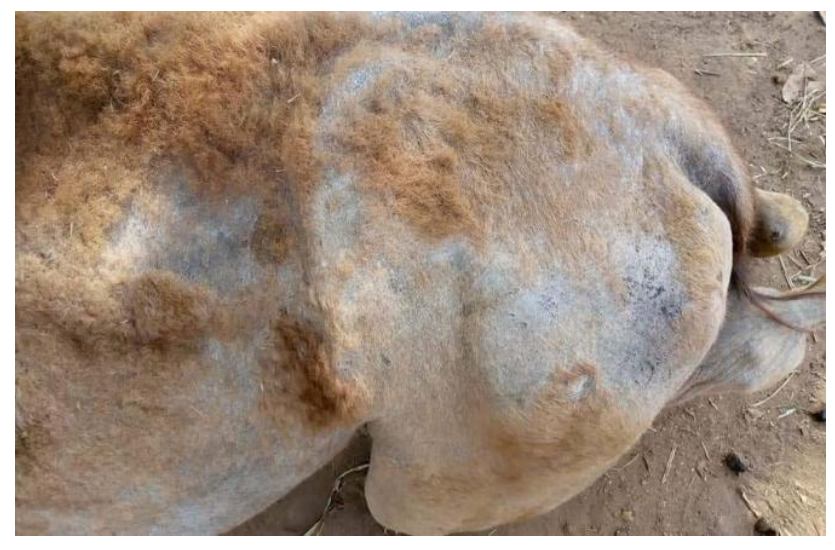

Fig.2 Camel with Sarcoptic mange

The hypoproteinaemia observed in the present study could be associated with the seepage of protein through exudation. Decrease in serum albumin could be a useful indicator of parasitism. Low level of albumin in affected camels of the present study could be due to loss of albumin as a result of dermatitis. Severity of hypoalbuminaemia could be related to loss of albumin or decreased synthesis due to inappetance. Hypoalbuminaemia occurs in starved animals (Kelly, 1983).

Globulin showed a decreasing trend in the diseased animals, as also reported by Parmar et al., 2005. Whereas AST, ALT and BUN were observed with increased concentrations as also supported by findings of Gorak Mal et al., 2006, Premalatha et al., 2010 and Arul, 2016 in camels infested with mange. AST and ALT activities varied according to the liver function which in turn varied according to the physiological and the health conditions of the animal, Sarwar et al., 2004. Bilirubin was observed with increased concentrations as also supported by findings of Momenah, 2014.

The Group 3 showed complete recovery in all the camels on $15^{\text {th }}$ day of treatment. It was also noted that camels in this group improved clinically earlierly and gained more weight than Group 1 and 2, which shows the efficacy of the drugs when used combinedly. Based on 
the report given by Fassi-Fehri (1987) who stated that malnutrition and nutritional deficiency (particularly vitamin A deficiency) favoured development of Sarcoptic mange, that is why we added Vitamin A in the Group 3.

$\mathrm{Hb}, \mathrm{PCV}$, TEC showed a decreasing trend than the normal range indicative of anemia in the diseased animals. Among the biochemical parameters, Total Protein, Albumin, Globulin was also decreased. TLC, Neutrophils, Eosinophils, Lymphocytes, Basophils, Monocytes and AST, ALT, ALKP, LDH, Bilirubin, BUN was increased. The treatment given to the Group 3 was best among the three therapeutic trial groups. This proves that $40 \%$ concentration of Neem applied once a week, for a total of four applications, Injection Ivermectin @ $0.2 \mathrm{mg} / \mathrm{kg} \mathrm{BW}$, once a week, for a total of four injections and Injection Vetade $10 \mathrm{ml}$ per camel, once a week, for a total of four injections was more efficient to cure sarcoptic mange in camels as compared to other trial groups.

\section{Acknowledgement}

The authors are highly thankful to the DEAN and management of Apollo College of Veterinary Medicine for their kind support during the course of this study.

\section{References}

Abdel-Rahman MB, Osman AY, Hunter AG. Parasites of the one humped camel (Camelus dromedarius) in Sudan: A review. Sudan Journal of Veterinary Research. 2001;17 :1-13.

Amer A, Abou El-Ela A, Ratib H. Some Haemato-biochemical studies on Sarcoptic mange infested camels before and after treatment by doramectin at Assiut governorate, In Proceedings of the International Scientific conference on Camels, KSA. 2006; 686-691.

Arora BM. Indian Wildlife Diseases and Disorders. Association of Indian Zoo and Wildlife Veterinarians, Bareilly. 2003.

Bekele M, Damena A, Bekele J, Adane B, Sheferaw DS. Ticks and mange mites infesting camels of Boran, Pastoral areas and the associated risk factors, southern Ethiopia. Journal of Veterinary Medicine and animal health. 2012;4(5) :71-77.

Dinka A, Eyerusalem B, Yacob HT. A study on major ectoparasites of camel in and around Dire Dawa, eastern Ethiopia. Revue de Medecine Veterinaire. 2010;161(11): 498-501.

Dr. Arul V. "Therapeutic management of scabies in a captive camel (Camelus dromedaries)". International Journal of Current Research. 2016;8(03): 2776827772.

Driot C, Kamili A, Faye B, Delverdier M, Tligui N. Study on the epidemiology and histopathology of Sarcoptic mange and ringworm in the one-humped camel in south of Morocco areas and the associated risk factors, Southern Ethiopia. Journal of Camel Practice and Research. 2011;18(1): 107-114.

Fassi-Fehri MM. Diseases of camels. Revue Scientifique Et Technique De L'Office International Des Epizooties. 1987;6(2): 337-354.

Georg SR. Parasitology to Veterinarians. W.R.Saunders. London. 1985

Gorak M, Sena DS, Sahani MS. Haematobiochemical changes in camels infested with mange during winter and summer season, Journal of Camel Practice and Research. 2006;13(2): 173174.

Kelly WR. Veterinary clinical diagnosis, 3rd Edn. Bailliere Tindall, London. 1983.

Kumar DS, Raisinghani PM, Manohar GS. Sarcoptic mange in camels: A review. 
In Proceedings of the first international camel conference, Dubai, UAE. 1992; 79-82.

Momenah MA. Some blood Parameters Of One Humped She-Camels (Camelus Dromedaries) In Response To Parasitic Infection. Life science Journal. 2014;11(5): 118-123.

Nayel NM and Abu-Samra MT. Sarcoptic mange in the one humped camel (Camelus dromedaries). A clinicopathological and epizootiological study of the disease and its treatment. Journal of Arid Environments. 1986;10: 199211.

Parmar AJ, Singh V, Chaudhry SS, Prajapati BH, Sengar YS. Haemato-biochemical studies on Sarcoptic mange in camel (Camelus dromedarius) in Banaskantha district (North Gujrat). Journal of Parasitic diseases. 2005;29(1): 71-73.

Pegram, R.G. and Higgins, A.J. (1992). Camel ectoparasites: A review. In: Proceedings: $1^{\text {st }}$ International camel conference, Dubai, UAE, 69-78.
Prajapati TVA and Raval S. Hematobiochemical changes in mange infection in camels. Life sciences leaflets. 2018;98: 26-29.

Premalatha N, Jayathangaraj MG, Senthilkumar K, Senthilvel K, Vengadabady N, Muralimanhar B Strategic treatment of scabies in captive camels (Camelus dromedarius) Tamilnadu. Journal of Veterinary and Animal Sciences. 2010;6(4): 188-190.

Rathod A, Singh AP, Dixit SK, Dadhich H, Tanwar RK, Gahlot AK. Haematobiochemical profile of camels (Camelus dromedaries) suffering from sarcopticosis. Veterinary practitioner. 2008;9: 104-109.

Richard D. Camel mange. Revue Scientifique et Technique De L'Office International Des Epizooties. 1987;6(2): 475- 477.

Sarwar A, Majeed MA, Hur G, Khan IR. Two transferases and four electrolytes in normal one-humped camel serum. Journal of Camelid Science. 2004;1: 57 61.

\section{How to cite this article:}

Aziz. P. R., S. Marodia, P. I. Ganesan and Sharma. C. S. 2020. Hemato-Biochemical and Therapeutic Trials on Sarcoptic Mange in Camels. Int.J.Curr.Microbiol.App.Sci. 9(03): 29062913. doi: https://doi.org/10.20546/ijcmas.2020.903.334 